\title{
REFLEXIONES SOBRE LA OBRA DE PIETRO CALAMANDREI: "EL ELOGIO DE LOS JUECES"
}

\author{
Por: Héctor Guillermo Campbell Araujo ${ }^{18}$
}

SUMARIO: I. Introducción. II. Características del juzgador. III.Relación entre formación-actuación. Conclusión

Resumen

¿Cómo debe ser un Juzgador?, ¿qué características y cualidades debe reunir? Son las interrogantes extraídas del texto "El elogio de los jueces escrito por un abogado" ----de Pietro Calamandrei--- que propician la reflexión sobre el ser y el deber ser de los jueces en su desempeño dentro del Poder Judicial.

Palabras Clave: Juzgador, cualidades, ser, deber ser

Abstract

How should a judge be? What features and qualities must he have? These are questions extracted from the text "The judges praise written by an attorney" - of Pietro Calamandrei - that encourage reflection on how judges are and how they ought to be in their performance within the judiciary.

Key words: Judge, qualities, to be, must be

\section{INTRODUCCIÓN}

¿Cómo debe ser un Juzgador?, ¿qué características y cualidades debe reunir? Para ser miembro de la Judicatura y para el desempeño de su función, con su experiencia en Italia durante el Fascismo y en la Postguerra (Segunda Guerra

18 Profesor Investigador de Tiempo Completo por oposición del Departamento de Derecho DCS de la Universidad de Sonora URC 
Mundial), el autor Piero Calamandrei ${ }^{19}$ nos señala descriptivamente como son algunos miembros del Poder Judicial y esboza como debieran ser.

La narrativa de Pietro Calamandrei, va describiendo la manera de actuar de los Jueces en su relación con los litigantes, con los políticos, con los maestros, con los usuarios, etc., su comportamiento cuando forman parte de los órganos de impartición de justicia y cuando dejan de serlo o con quienes dejan de serlo.

A través de esta descripción va denotando ciertos defectos de los cuales algunos adolecen y ciertas virtudes que poseen o debieran poseer, sean evidentes o subyacentes, realizando una crítica sutil y busca sin imponerlo un prototipo de Juzgador que el propio lector habrá de construir con base en lo señalado en la lectura.

A pesar del tiempo transcurrido desde la aparición de la obra de Pietro Calamandrei, (1940) no deja de estar vigente e inclusive el lector, que de manera cotidiana o casualmente, ha coincidido en un órgano de impartición de justicia no dejará de sentirse identificado con algún personaje o situación similar a las descritas por el autor.

De igual manera ocurre en cuanto al ámbito geográfico, no obstante que se refiere al Poder Judicial Italiano, ignoro si sea por el antecedente del Derecho Romano en nuestro sistema jurídico o por la simple naturaleza humana prevalece la similitud a que nos referíamos en el párrafo precedente.

${ }^{19}$ Catedrático de la Universidad de Florencia y diputado en el Parlamento Italiano, Pietro Calamandrei fue, junto a Carnelutti y Enrico Redendi, uno de los principales inspiradores del Código de Procedimiento Civil Italiano de 1940. Discípulo de la escuela de Giussepe Chiovenda, Calamandrei es, sin duda, uno de los más destaca dos procesalistas de finales del siglo XX. Miembro de la prestigiosa Academia Nazionale dei Lincei, director del Instituto de Derecho Procesal Comparado de la Universidad de Florencia, director, con Carnelutti, de la "Revista de Derecho Procesal" y de la revista "El Foro Toscano" (junto a Finzi, Lessona y Paoli), del Comentario Sistemático de la Constitución Italiana y fundador de la "Revista Cultural II Ponte". http://www.casadellibro.com/libro-elogio-de-los-jueces-escrito-por-un abogado/9788429015775/1624644[consultado en 7 de octubre de 2013] 


\section{Características del juzgador}

El juzgador, es un simple y mortal ser humano, como tal imperfecto y debería recordársele como a los Cesares, con una cuota de poder que administrar. Lo anterior nos lleva no solo a desacralizarlo, sino a impulsarlo a que busque la perfección en el desempeño de su función, como todo ser humano no es perfecto pero debe buscar serlo, es el primer compromiso de todo persona.

Somos muy dados a los estereotipos negativos, tenemos nuestras imágenes de como son las personas podemos coincidir en describir a los políticos, a los adictos, a los jueces a los abogados, etc., e incluso a afirmar que todos son iguales. Los políticos siempre son rateros, los adictos desaseados, los jueces soberbios, los abogados mentirosos.

Creo que lo anterior nos lleva a perder la perspectiva original, todos son seres humanos, y como tales, tendrán quizás su verdad, pero ¿qué es la verdad?

- Los filósofos (predominantemente los de la escuela analítica) suelen aceptar que la verdad (o la falsedad) es una propiedad que sólo tienen los portadores de verdad.

- Por definición, los portadores de verdad son aquéllos objetos que pueden adquirir un valor de verdad (ya sea Verdadero, Falso u otro, si es que existen más).

Pero además de acuerdo a esa verdad tendrá que actuar, y entonces es un problema de Deontología. El término deontología proviene del vocablo griego deon, deber, y logos, razonamiento o ciencia.Deontología, por tanto, es para Hébarre "el conjunto de reglas de carácter ético que una profesión se da a sí misma y que sus miembros deben respetar". 
El concepto deontología fue acuñado por Jeremías Bentham en su obra "Deontología o ciencia de la moral", en donde ofrece una visión de esa disciplina que no ha sido, sin embargo, compartida por todos los estudiosos del tema.

Para Bentham, la deontología se aplica fundamentalmente al ámbito de la moral, es decir, a aquellas conductas del hombre que no forman parte de las hipótesis normativas del derecho vigente. Trata, pues, del espacio de la libertad del hombre sólo sujeto a la responsabilidad que le impone su conciencia.

Bentham considera que la base de la deontología se debe sustentar en el principio de la utilidad, lo cual significa que los actos buenos o malos de los hombres sólo se explican en función de la felicidad o bienestar que puedan proporcionar (mayor bienestar posible).

Para Kant la deontología es en sí misma una ciencia de los deberes o imperativos categóricos en la que no importan los fines, sino la intencionalidad del acto, independientemente de las consecuencias materiales de aquél. La base de la ética kantiana se encuentra en el siguiente principio básico: "Obra siempre de acuerdo con aquella máxima que al mismo tiempo puedes desear que se convierta en ley universal". Y eso quiere decir que una persona actuaría éticamente si está de acuerdo en que su regla de conducta debe ser aplicada por todo aquel que se llegara a encontrar en una circunstancia similar.

Para Kant la deontología es en sí misma una ciencia de los deberes o imperativos categóricos en la que no importan los fines, sino la intencionalidad del acto, independientemente de las consecuencias materiales de aquél. La base de la ética kantiana se encuentra en el siguiente principio básico: "Obra siempre de acuerdo con aquella máxima que al mismo tiempo puedes desear que se convierta en ley universal". Y eso quiere decir que una persona actuaría éticamente si está de acuerdo en que su regla de conducta debe ser aplicada por todo aquel que se llegara a encontrar en una circunstancia similar. 
De lo anterior podemos precisar que en un sentido etimológico, Deontología hace referencia a la ciencia del deber o de los deberes:

Y la Deontología Jurídica es la rama de la filosofía jurídica que tiene como finalidad específica la determinación de cómo debe ser el Derecho y cómo debe ser aplicado.

La importancia práctica de la deontología jurídica la pone de manifiesto Vanni, haciendo ver la relación que existe entre las formaciones sociales y la actividad psíquica de los hombres.

Luego entonces cuales son los deberes que el impartidor de Justicia tiene en su actuación, pues como todo ser humano integral, tiene deberes, morales, éticos y jurídicos/legales, y debe conciliar todos ellos para ser un individuo congruente.

Para efectos de este ensayo Moral, de etimología latina mosmore. Es el conjunto de valores sanos, sociales (honestidad, buenas costumbres, honradez y el respeto al derecho de los demás.)

Concepto personal del bien y el mal, formado a través de la influencia de la familia, la cultura y la sociedad, nos otorga los valores morales.

Etica proviene del griego ethikos ("carácter"). Se trata del estudio de la moral y del accionar humano para promover los comportamientos deseables.

Una sentencia ética supone la elaboración de un juicio moral y una norma que señala cómo deberían actuar los integrantes de una sociedad. Pretende regular las actividades que se realizan en el marco de una profesión.

En este sentido, se trata de una disciplina que está incluida dentro de la ética aplicada ya que hace referencia a una parte específica de la realidad.

La ética, a nivel general, no es coactiva (no impone sanciones legales o normativas). Sin embargo, la ética profesional puede estar, en cierta forma, en los códigos deontológicos que regulan una actividad profesional. La deontología forma 
parte de lo que se conoce como ética normativa y presenta una serie de principios y reglas de cumplimiento obligatorio.

Estudia las normas vinculantes recogidas por la deontología profesional. La ética sugiere aquello que es deseable y condena lo que no debe hacerse, mientras que la deontología cuenta con las herramientas administrativas para garantizar que la profesión se ejerza de manera ética.

Vinculado con la Ética y la Ética Profesional, La axiología no sólo trata de los valores positivos, sino también de los valores negativos, analizando los principios que permiten considerar que algo es o no valioso, y considerando los fundamentos de tal juicio.

La investigación de una teoría de los valores ha encontrado una aplicación especial en la ética y en la estética, ámbitos donde el concepto de valor posee una relevancia específica.

Algunos filósofos como los alemanes Heinrich Rickert o Max Scheler han realizado diferentes propuestas para elaborar una jerarquía adecuada de los valores. En este sentido, puede hablarse de una 'ética axiológica', que fue desarrollada, principalmente, por el propio Scheler y Nicolai Hartmann.

Desde el punto de vista ético, la axiología es una de las dos principales fundamentaciones de la Ética junto con la deontología.

El método trascendental de Lonergan postula que ninguna ciencia puede prescindir del ámbito de los valores.

El Derecho no puede prescindir de la Ética, y que también debe estar atento a respetar los ordenamientos de la Moral. 


\section{Relación entre formación-actuación}

Considerando que la función Judicial, está inmersa en el campo del Derecho, también está sujeta a la Moral, Ética, Ética Profesional, Deontología, Deontología Jurídica, y por tanto con la Axiología, y esto nos lleva a distinguir y relacionar:

El Juzgador como cualquier ser humano, asume una escala de valores, su concepto del bien del y del mal, a la cual trata de constreñir su actuación.Por ende debe ser congruente con su moral, pero esta debe embonar en lo que es éticamente aceptable y jurídicamente esperado.

El juzgador ideal no existe, impartir justicia no es una simple operación aritmética, ni tampoco es un capricho o frivolidad.Impartir justicia es un gran esfuerzo de razocinio, aun la resolución mas disparatada requiere comprensión por mas injustificable que nos parezca.

Sin duda alguna el Juez pone su sello personal en sus relaciones, su impronta, su firma, que viene de su naturaleza humana, peculiaridades y particularidades que su experiencia propia le va determinando.

Cuantas veces el litigante exige que se le resuelve se le resuelve pronto, sin siquiera ver el fondo del sentido de la resolución; por contrapartida cuantas veces se exige demórate lo necesario, pero resuelve bien.

No defiendo al Juez, pero para los litigantes si es saludado por el Magistrado este es chacotero y vacilador, y si no lo saluda es soberbio o engreído; si le recibe a solas hay contubernio, si lo atiende en público no hay discreción.

Luego entonces al Juzgador solo le queda en solitario determinar y establecer la moral, la ética con la que habrá de comportarse y actuar conforme a esta, que debemos esperar sea apegada a Derecho, más allá de las simpatía o antipatía personales y concretas que pueda desarrollar. 
Recordando a Kelsen, justicia en ocasiones se equipara a legalidad, lo justo es aplicar la norma a aquellos casos que debe aplicarse, e Injusto es aplicar la regla en un caso y dejar de aplicarse en otro.

Para nuestro clásico García Máynez, derecho vigente, derecho intrínsecamente válido y derecho eficaz, y la confluencia ideal/utópica de los tres círculos, cual debe aplicar el juzgador.

Para Bobbio "La revuelta contra el formalismo", cuestiona si son sinónimos positivismo y formalismo jurídico, porque entonces, habría que hablar de formalismo ético, y distinguir entre la forma y el contenido.

\section{A MANERA DE CONCLUSIÓN}

Luego entonces ¿Cuál postura debe asumir el Magistrado Judicial al impartir justicia?:

¿Ser simplemente el aplicador de la Ley, sin emitir juicios de valor?

¿Tasar más alto el valor de la amistad que el de la justicia?

¿Desdeñar la justicia por la política?

¿Ser positivista y no considerar el Derecho Natural?

¿Declararse naturalista y así desdeñar al Derecho Positivo?

¿Seguir una línea del menor daño posible?

¿Teórico o práctico?

¿Dogmático o ecléctico?

¿Declinar el asunto o renunciar al empleo cuando tenga conflictos de conciencia?

¿Sus resoluciones deben ser objetivas o subjetivas? 
BIOLEX

Revista Jurídica del Departamento de Derecho UNISON URC

Academia de Derecho Administrativo

Tercera Época Año 4. No 8 Enero a Julio de 2013

¿Qué es lo Justo o lo injusto, lo equitativo y lo inequitativo?

\section{Referencias Bibliográficas y Webgráficas}

Bobbio, Norberto, El problema del positivismo jurídico, Ed. Universitaria de Buenos Aires, 1965; reeditado en Fontamara, México, 1991.

Calamandrei Pietro,Elogio de los jueces escrito por un abogado, Ed. REUS, México,2009 